\title{
Experimental study of thermal comfort in a vehicle cabin during the summer season
}

\author{
Paul Danca ${ }^{1,2}$, Florin Bode ${ }^{1,3}$, Angel Dogeanu ${ }^{1}$, Cristiana Croitoru ${ }^{1}$, Mihnea Sandu ${ }^{1}$, Amina Meslem ${ }^{2}$ and Ilinca Nastase $^{1, *}$ \\ ${ }^{1}$ CAMBI Research Center, Technical University of Civil Engineering Bucharest, 021414 Bucharest, Romania \\ ${ }^{2}$ IUT Rennes, Laboratoire Génie Civil Génie Mécanique 35704 Rennes Cedex 7 France \\ ${ }^{3}$ Technical University of Cluj Napoca, Department of Mechanical Engineering 400020 Cluj - Napoca, Romania
}

\begin{abstract}
Thermal comfort evaluation for vehicle occupants is very complicated due to the transient nature and non-uniformity of the vehicle interior. The thermal sensation of an automotive occupant is affected by the surrounding environment. More than this, the actual standard is proposing three evaluation indexes and was developed for steady state and controlled conditions and some of the indexes are not adapted for this complex environment. In this article the three standardized indexes values are compared in term of thermal comfort, in a vehicle passenger in summer season. The results are showing that the mean values of PMV/PPD model calculated in a single point with Comfort Sense equipment are far from the TSV mean values which was collected in questionnaires, while the teq index which was calculated with an advanced thermal manikin are closer to the TSV comfort votes. This may be explained by the fact that the TSV and teq consider the sensation for each body part at the local level. For a correct evaluation of the thermal comfort in non-uniform and transient environments like in the vehicles, is not enough to measure in a single point and the results to be considered in all the ambiance. The main conclusion is that the PMV/PPD indexes are not very well adapted to the vehicle environment.
\end{abstract}

\section{Introduction}

We can find many studies in the literature [1-10] for the automobile thermal environment evaluation and thermal comfort of the occupants in the vehicles cabin but these domains are not fully explored because of the increasing demand for better comfort condition to the vehicle occupants and this together with the reduction of the energy consumption.

The vehicle cabin environment is very complex and different in comparation with the buildings environment. It is characterized by a multitude of factors (as the solar direct and defused radiation, the large difference between temperatures on the interior surfaces, the high velocity in some zones of the vehicle interior), with values that change very quickly. Also, the distribution of the values of the factors is not uniform though this environment.

The actual standard in use which proposes evaluation methods for the vehicle interior environment is ISO 14505/3 [11-13] divided in three parts. The standardized evaluation methods in this standard were developed more than 50 years ago for the building environment and unfortunately are more or less adapted for the vehicle interior environment.

Due to transient characteristic and non-uniform distribution of the thermal factors related to the vehicle cabin and to the fact that the actual standardized evaluation methods are obsolete we distinguish three directions of research for the vehicle cabin environment. In a first category are included studies with the aim to characterize thermal environment of the vehicle cabin $[14,15]$, without evaluation of occupants thermal comfort; another category is composed by those studies in which are proposed or are tested new evaluation methods $[1,2,16]$; in the third category for the evaluation of the thermal comfort are the three models: in the third category for the evaluation of the thermal comfort are the three models (PMV/PPD model; TSV model; t teq model) proposed by standard [11-13].

Usually in the studies from the third category there are comparisons between the thermal comfort models proposed by the actual standard [11-13]. Almost all studies find differences between the results obtained through the compared thermal comfort models. The actual study belongs to the third direction of research for the vehicle cabin environment. In this study the vehicle cabin environment is evaluated using the three standardized evaluation methods proposed by ISO 14505 standard and the resulting values are compared.

\footnotetext{
* Corresponding author: ilinca.nastase@gmail.com
} 


\section{Experimental set-up}

The experimental facility is composed of a Renault Megane hatchback car with a 1.4 liter engine, with a manual ventilation/conditioning system. The vehicle was kept inside a hall (see Fig. 1) were indoor conditions varied much slower than outside. The main reason for this choice was related to our desire to maintain constant values of the vehicle external factors, to decouple the in-cabin conditions from the solar radiation effect. The sessions for the thermal comfort measurement were made during 2 days with similar external conditions. Inside the hall where the experimental vehicle was placed, air temperature was around $40^{\circ} \mathrm{C}$. Air temperature variation is represented in Fig. 2. In each of the two days before each measurement sessions, the engine was turned on for 30 minutes [13].

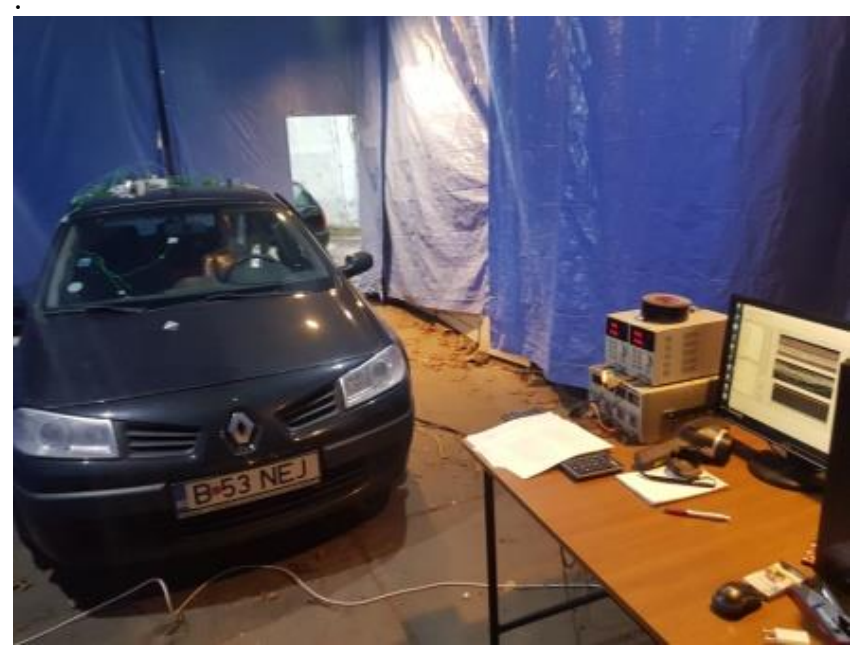

Fig. 1. Experimental car in the hall

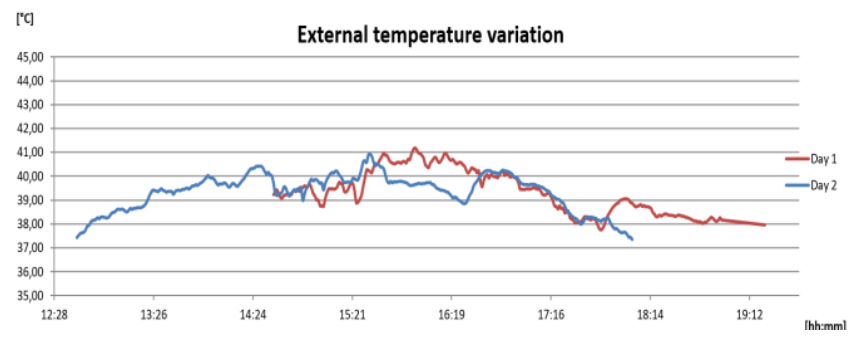

Fig. 2. Temperature variation in hall

For temperature monitoring, inside cabin was installed a network of 27 k-type thermocouplesEroare! Fără sursă de referință.. These were connected to 3 data loggers manufactured by Ahlborn: two Almemo 710 each with 10 sensor connecting ports available, one Almemo 2890-9 with 9 sensor connecting ports available. The thermocouples were placed as follows: three thermocouples were placed at the inlets: one in the central diffuser, one on the left side diffuser and another in the right-side diffuser. Another nine thermocouples were placed on the interior surface: dashboard, windshield, sides windows, ceiling, floor, top of the trunk and rear window. Another fifteen were placed in the places where normally sensible parts of human body are as: head, chest, abdomen, knee and ankles. In Fig. 3 are presented the thermocouples distribution inside the car.
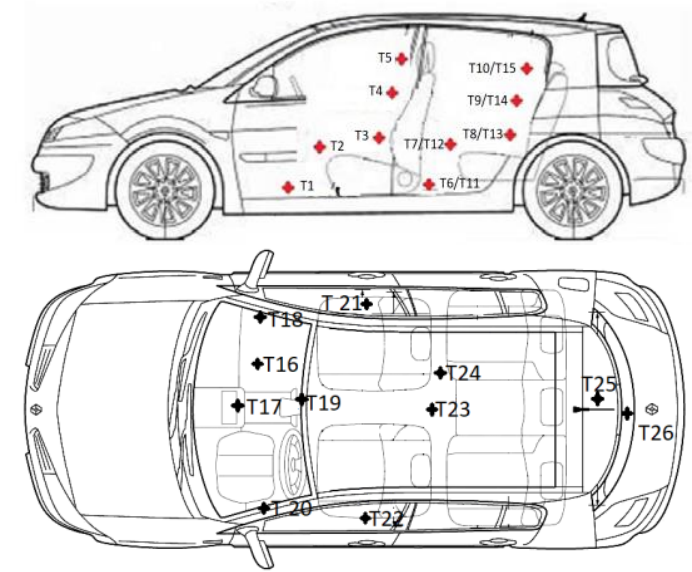

Fig. 3. K-type thermocouples distribution in the cockpit

Thermal comfort evaluation of the vehicle interior was made following the guidelines of the ISO $14505 / 3$. This standard proposes three evaluation methods with different procedures.

In the first part of the standard [11] is proposed the method developed by Fanger [17]. PMV and PPD indexes are calculated by a Comfort Sense equipment placed inside the vehicle.

Another procedure that is proposed in the second part of the standard is the calculation of the Equivalent temperature index ( $\left.\mathrm{t}_{\mathrm{eq}}\right)$ [12]. An advanced thermal manikin with 79 zones independently controlled was used to asses vehicle environment via $t_{\text {eq }}$ index.

The method described in the third part of the standard [13] implies human subjects. TSV index is resulting from the questionnaires surveyed by volunteers. The questions form the questionnaire used in our study were chosen with regards to ISO 14505-3 and ISO 10551/2001 [18] which covers the construction and use of thermal sensation scales and proposes a set of specifications on direct experts assessment of thermal comfort/discomfort expressed by persons subjected to various degrees of thermal stress.

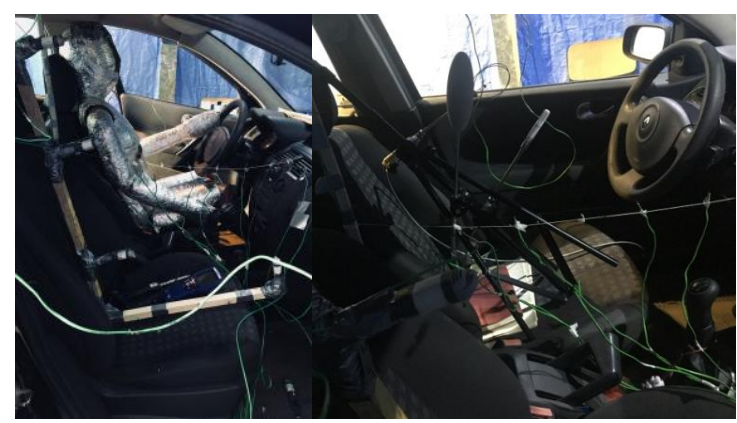

Fig. 4. Images during the experimental sessions with thermal manikin and CS

Totally, a number of 11 measurement sessions were preformed, each lasting 45 minutes. Thermal comfort was assessed for the first three positions of the ventilation/climatization system like in Fig. 5. For each position, 4 questionnaires were filled as following: one at the beginning of the session, then after 5 minutes, after 
10 minutes and after 15 minutes. Air-conditioned system was turned $\mathrm{ON}$ during all the measurement sessions. Cold air was introduced in to the cabin only through the front dashboard diffusers.
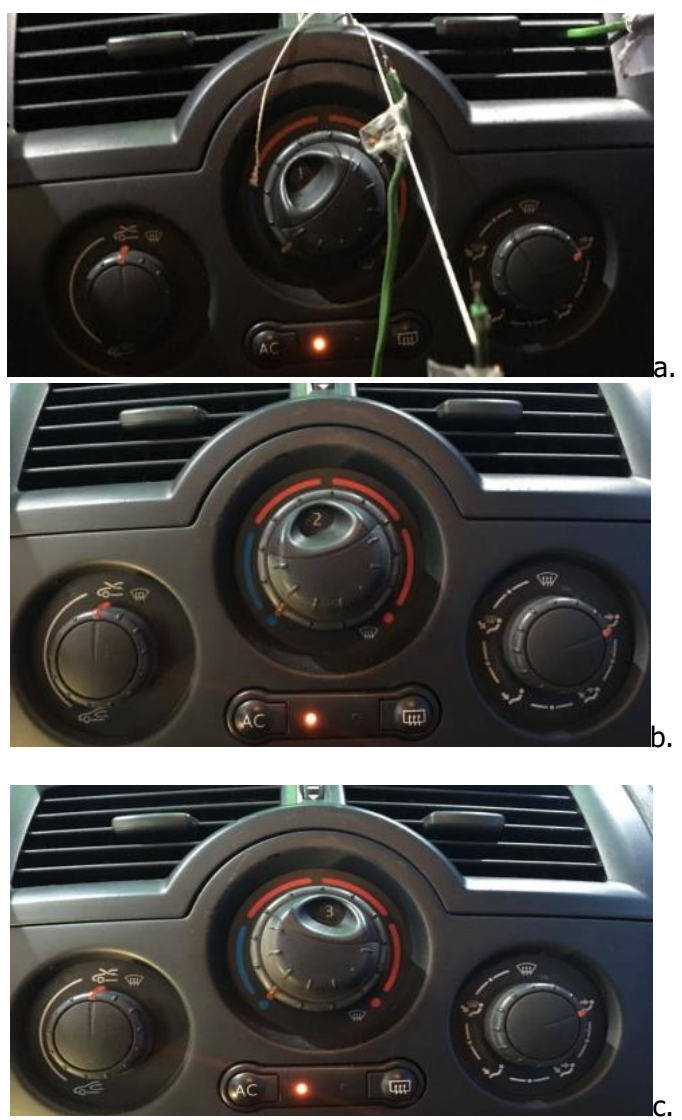

Fig. 5. Setup of the three position of the ventilation/climatization system a. V1, b. V2, c. V3

In two of the experimental campaigns, Suzy thermal manikin and the Comfort Sense system were placed on the driver place and in other nine of them volunteers. Excluding the session when the Comfort Sense was placed on the driver place, in the other session his probes was in the center of the car. This practice is often meet in similar studies from the available literature.

The temperature of the manikin's surface had the anatomical distribution as in the standard [12]. In our opinion this is the most adapted evaluation tool because is considering the heat transfer between the body and environment. While the PMV/PPD indexes is calculated in a single point and is supposed to consider the resulting value all over the cabin environment. Knowing that this environment is not uniform we can say that a local evaluation in a single point is not showing a realistic value of the thermal comfort state. However, this is one of the standardized indexes.

The survey study was conducted on a limited sample of volunteers, but the demands of the standard ISO 14505-3 were followed, a minimum of 8 people being required. The 9 volunteers are between 27 and 49 years of age, 7 of them are men and 2 women. Survey questionnaires were given to the occupants and a total number of 108 questionnaires were completed. The time for filling the questionnaire was about $30-60 \mathrm{sec}$.

\section{Results and discussions}

The results obtained with the three standardized methods will be presented in the first part of this chapter and in the second part a comparison between the methods is made.

In Fig. 6 we can see the mean temperature of the introduced air in the vehicle for all three airflow rates in the right, center and left diffusers. By increasing the airflow rate, we observe an increment of the introduced air temperature. Also, we can remark a large difference for the temperature of the introduced air through the diffusers for the first and second position of the ventilation/climatization position.

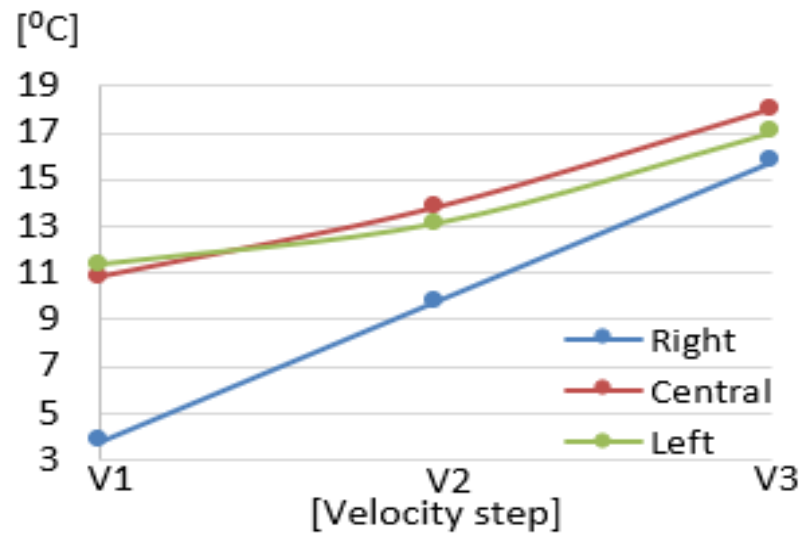

Fig. 6. Inlet jet air temperature

Mean values of the temperature from the interior surfaces and from center of the vehicle are presented in Fig. 8 and Fig. 7. The temperature recorded in the center is decreasing with $5.5^{\circ} \mathrm{C}$ between for $\mathrm{V} 2$ and $\mathrm{V} 3$ comparing to V1. Between V2 and V3 there is not much difference because the introduced air has a higher temperature and the higher velocity of the inlet jet which is impinging it through all the environment to the rear part of the car.

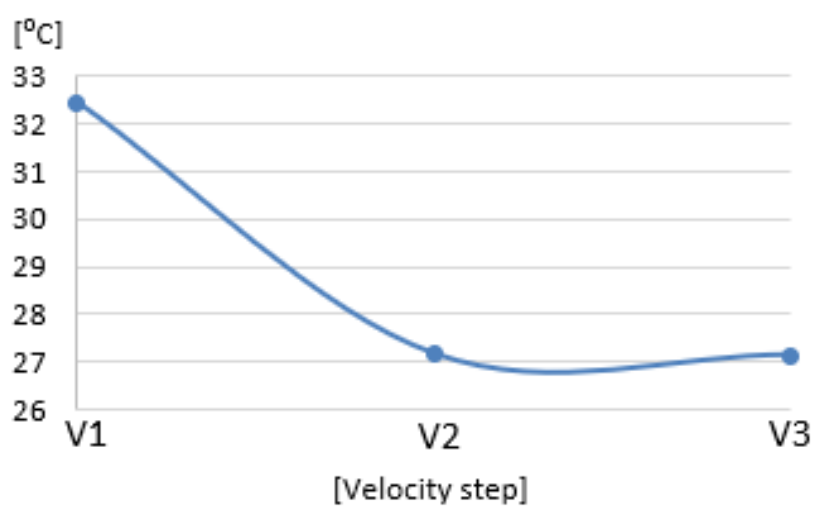

Fig. 7. Temperature variation in the center of the car 


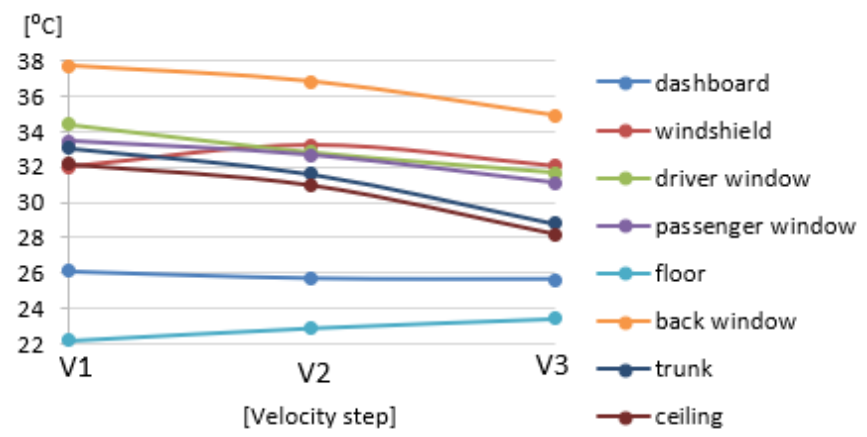

Fig. 8. Temperature variation on the interior surfaces

The results assessed with the thermal manikin are presented in Fig. 9. In the shown diagrams with 1, 2, 3, 4 and 5 are represented comfort sensations corresponding to too cold, cold but comfortable, neutral, warm but comfortable, too hot thermal sensations. To each sensation is corresponding differed ranges of $t_{\text {eq }}$ values specific for each zone. This ranges are presented in ISO 14505-2 [12] . As it can be seen in Fig. 9 the thermal manikin is assessing a high uncomfortable cold sensation for right upper arm placed on the direction of the inlet airflow which is coming from the central diffusers. Some of the regions as chest, left leg, left foot, right arm and left arm are near the region of cold sensation but still in the comfortable thermal sensation zone. The $t_{\text {eq }}$ of the other body parts are in the zone 3 which is a neutral sensation.

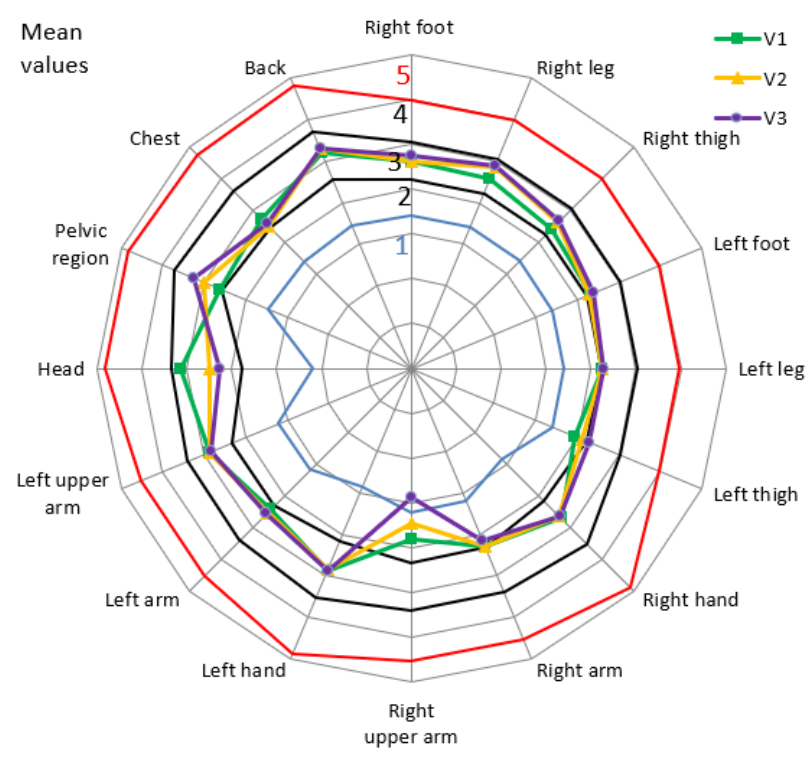

Fig. 9. Distribution of the mean $t_{\text {eq }}$ values.

In Fig. 10 are presented the percentages of thermal sensations resulting from the questionnaires completed by the 9 human subjects for the three positions of the air flowrate of the ventilation/climatization system.

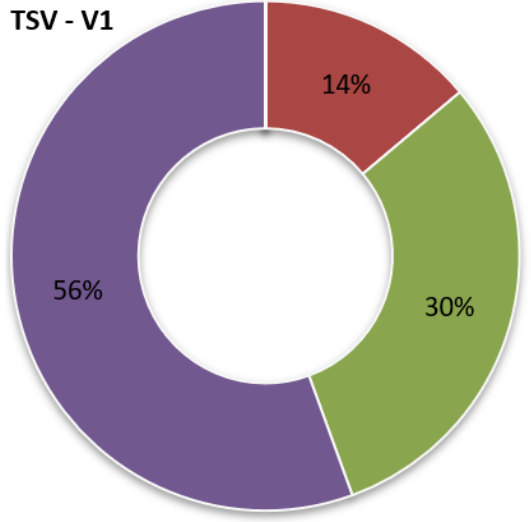

- $+3 \mathrm{Hot}$

- +2 Warm

-1 Slightly warm

- 0 Neutral

- -1 Slightly cool

-2 Cool

- -3 Cold

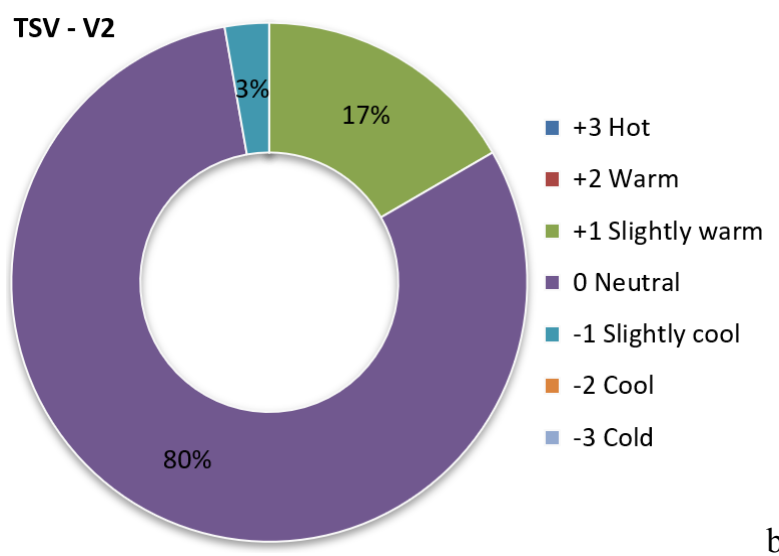

b.

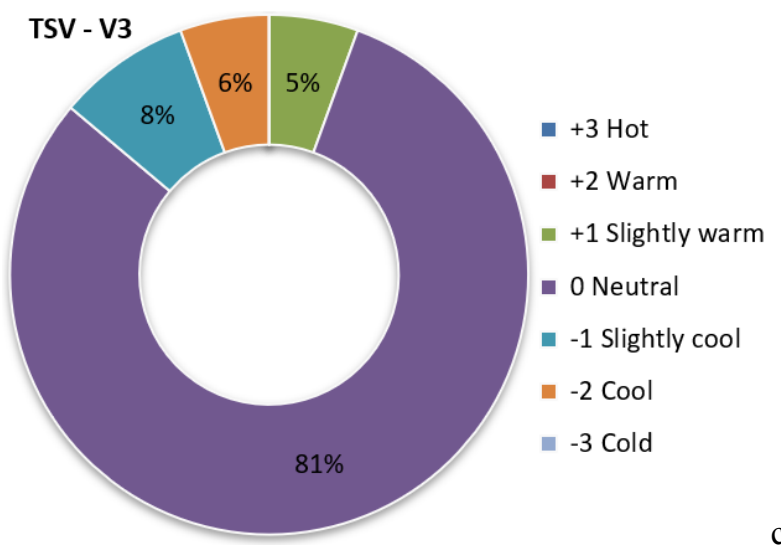

c.

Fig. 10. Percentages of thermal sensations from the questionnaires for the three velocity positions.

As can be seen, for the lower air flowrate (V1), 14\% of the human subjects express a warm sensation and the general tendency for this case is to vote for the slightly warm option. For the higher air flowrate (V3), $6 \%$ of the passengers asses a cool sensation and the general tendency is showing a slightly cool sensation due to the higher air velocities. For the second position (V2) the majority percentages of the expressed votes are around neutral sensation. In our perception, for this situation the second air flowrate position (V2) seems to provide better comfort sensation than the other flowrates.

In Fig. 11 are presented the values of PMV assessed with the Comfort Sense probes placed in the center of the vehicle cabin and on the place of the driver. 


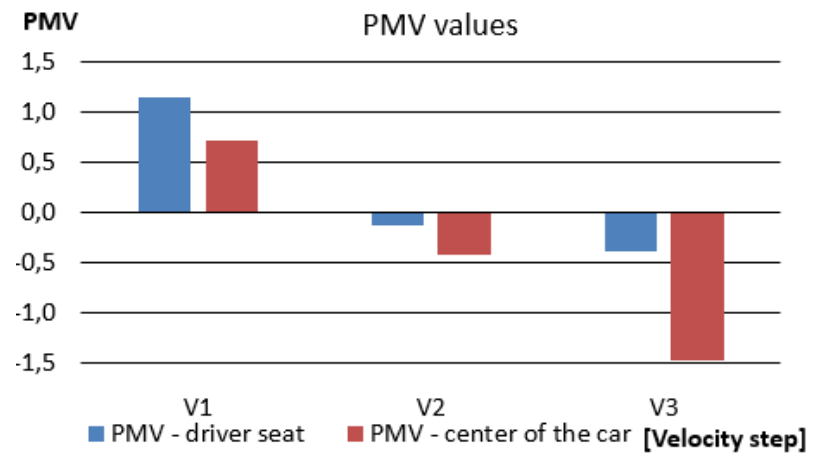

Fig. 11 PMV values in center of the car and on the driver place for the three position of the ventilation/climatization system.

The PMV values are presented in this manner to highlight that the place of the measurement probes is very important when thermal comfort is evaluated in a such complex and non-uniform environment. In some articles we can find that the authors placed the measurement probes in the center of the vehicle and the resulting value was for all the environment $[1,19,20]$. From this graph we can see the PMV values assessed in the two places are not similar. For the first air flowrate position (V1) we can see that on the place of the driver we have a slightly warm sensation while in the center the tendency is to neutral state. This can be explained by the air flowrate from the central diffusers which is passing to the proximity of the velocity probe and cools down that region. Also, a high discrepancy can be seen in the case of the third air flowrate position (V3) when the PMV from center is showing a cool thermal state. This is due to the high velocity of the air passing through the center of the vehicle. For this case, for example, the PMV index value from the driver place is in the comfort ranges.

In the second part of this chapter are compared the recorded values of the three standardized indexes. The comparation of mean values of PMV index with TSV index values are presented in Fig. 12. Both indexes use the same seven points sensation scale.

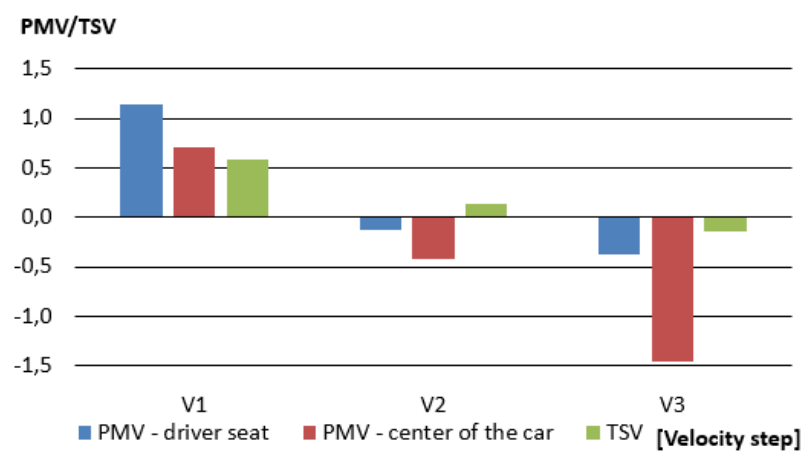

Fig. 12 comparison between the PMV and TSV indexes

At first sight is obvious that the PMV values recorded on the driver place are closer to the TSV values resulting from the questionnaires, while the PMV values recorded in the center of the vehicle are far from the TSV values. Again, we can see the importance of the measurement point. The small differences between the results of these two indexes in the driver place may be explained by the fact that the PMV is calculated in a single point while the TSV value is considering the sensations of each human body part.

In Table 1 are exposed mean values of the standardized indexes for the three ventilation/conditioning system position.

Table 1. values of thermal comfort evaluation indexes

\begin{tabular}{|c|c|c|c|c|}
\hline \multirow{2}{*}{$\begin{array}{c}\text { Index/ } \\
\text { Velocity }\end{array}$} & teq & TSV & $\begin{array}{c}\text { PMV - } \\
\text { driver seat }\end{array}$ & $\begin{array}{c}\text { PMV - } \\
\text { center of } \\
\text { the car }\end{array}$ \\
\cline { 2 - 5 } & {$\left[{ }^{\circ} \mathrm{C}\right]$} & {$[-]$} & {$[-]$} & {$[-]$} \\
\hline V1 & $\begin{array}{c}22,76 \text { (cold } \\
\text { but } \\
\text { comfortable) }\end{array}$ & $\begin{array}{c}0,58 \\
\text { (slightly } \\
\text { warm) }\end{array}$ & $\begin{array}{c}1,15 \\
\text { (warm) }\end{array}$ & $\begin{array}{c}0,72 \\
\text { (slightly } \\
\text { warm) }\end{array}$ \\
\hline V2 & $\begin{array}{c}22,80 \text { (cold } \\
\text { but } \\
\text { comfortable) }\end{array}$ & $\begin{array}{c}0,14 \\
\text { (neutral) }\end{array}$ & $\begin{array}{c}-0,12 \\
\text { (neutral) }\end{array}$ & $\begin{array}{c}-0,41 \\
\text { (neutral) }\end{array}$ \\
\hline V3 & $\begin{array}{c}22,77 \text { (cold } \\
\text { but } \\
\text { comfortable) }\end{array}$ & $\begin{array}{c}-0,14 \\
\text { (neutral) }\end{array}$ & $\begin{array}{c}-0,38 \\
\text { (neutral) }\end{array}$ & $\begin{array}{c}-1,46 \\
\text { (cool) }\end{array}$ \\
\hline
\end{tabular}

For all three studied cases, the thermal manikins show the same thermal sensation, cold but comfortable. Also, the TSV values are remaining in the neutral ranges. Thermal sensations resulting PMV index values in the driver place are similar to the other indexes, excepting V1 flow rate position where a warm thermal sensation was found. As previously was mentioned this difference can result from the fact that PMV is a punctual evaluation index, while the other two takes into account local sensations of each body part.

\section{Conclusions}

This paper is focused on the transient non-uniform environment inside the automotive passenger compartment. Determination of the vehicle occupants thermal comfort is very complicated due to the transient nature and non-uniformity of the vehicle interior. More than this, the actual standard is proposing three evaluation indexes and was developed for steady state and controlled conditions and some of the indexes are not adapted to this complex environment.

In this article are compared the values obtained for the three standardized indexes in term of thermal comfort, in a vehicle passenger in summer season.

The results are showing that the mean values PMV/PPD model calculated in a single point with Comfort Sense equipment are far from the TSV mean values resulting from questionnaires survey with human subjects, while the teq index was calculated with an advanced thermal manikin are closer to the TSV comfort votes. This may be explained by the fact that the TSV and teq consider the sensation for each body part at the local level.

For a correct evaluation of thermal comfort in nonuniform and transient environments like in the vehicles, is not enough to measure in a single point and the results to be considered in all the ambient. The main conclusion 
is that the PMV/PPD indexes are not very well adapted to the vehicle environment.

\section{Acknowledgment}

This work was supported by the grants: of the Romanian space agency ROSA, QUEST - Advanced air diffusion system of the crew quarters for the ISS and deep space habitation systems, STAR-CDI-C3-2016-577.

\section{Nomenclature}

PMV Predicted Mean Vote

PPD Predicted Percentage of Dissatisfied

TSV Thermal Sensation Vote

teq Equivalent temperature

\section{Bibliography}

1. A. Alahmer, M. Omar, A. R. Mayyas, A. Qattawi, Build. Env. J 48. 146-163 (2012)

2. A. Alahmer, M. Abdelhamid, M. Omar, Therm. Eng. J. 36, 126-140 (2012)

3. P. Danca, F. Bode, I. Nastase, A. Meslem, E3S Web of Conf. 32, 8 (2018)

4. M. Yiyi, W. Ji, L. Junming, Appl. Therm. Eng. 137, 356-367 (2018)

5. M. Kilic, S.M. Akyol, Heat Mass Transfer 48, 1375-1384 (2012)

6. W. Zhang, J. Chen, F. Lan, Chinese Journal of Mechanical Engineering (2014)

7. F. Bode, I. Nastase, P. Danca, A. Meslem, CIEM, 4, 2017

8. P. Danca, F. Bode, I. Nastase, A. Meslem, Energy Procedia, J. 112, 656-663 (2017)

9. P. Danca, F. Bode, I. Nastase, C. V. Croitoru, A. Meslem, E3S Web of Conf. 85, 6 (2019)

10. T. Horobet, P. Danca,I. Nastase, F. Bode, E3S Web of Conf. 32, 6 (2018)

11. ISO: EN ISO 14505 - 1: 2007 (2007)

12. ISO: EN ISO 14505 - 2: 2006 (2006)

13. ISO: EN ISO 14505 - 3: 2006 (2006)

14. Q. Chunling, H. Yaxin, L. Jiying, Z. Linhua, Procedia Eng. 205, 7 (2017)

15. T. Dehne, P. Lange, A. Volkmann, D. Schmeling, M. Konstantinov, J. Bosbach, Build. and Envir. 129, 11 (2018)

16. K. Nagano, T. Horikoshi, Energ. Build. 43, 7 (2011).

17. P. O. Fanger C.D.T. Press. 1970

18. ISO: EN ISO 10551:2001 (2001)
19. L. Tzu-Ping, H. Ruey-Lung, H. Kuo-Tsang, S. Chen-Yi, H. Ying-Che, Biometeorology J. 54(3), 221-230 (2010)

20. T. Orzechowski, Z. Skrobacki, EPJ Web of Conferences 114, 02085 (2016) 